\title{
On Post 90s Undergraduates How to Realize the Change from "Students" to "Learners"
}

\author{
Ping Zhang, Guozhu He*, Yan Zhao \\ Sichuan Agricultural University, 611830, Dujiangyan, China \\ heguozhu@sicau.edu.cn
}

\begin{abstract}
The key for academic education to promote the post 90 s undergraduates to become a generation with a sense of responsibility is to help them realize the change from "students" to "learners". By doing this, they can independently pursue continuous growth in knowledge, intelligence and morality in the process of career planning so as to assume the responsibility of exploring a happy life.
\end{abstract}

\section{Keywords-post 90s; learners; happy life}

The post 90s undergraduates have been the majority in the university students group and the marks of age process labeled on them are gradually arresting attention. In 1990s, the realities that the peaceful development of China's society began to take wing, that the establishment of Socialist market economy system has burst forth strong economic vitality, and that China waved goodbye to the shortage economy and came to embrace the surplus economy era have raised the curtain for life in a consumer society. Moreover, the implementation of the national policy of family planning started from 1980s has determined that most of the post $90 \mathrm{~s}$ undergraduates are the only child in their families, who became the center of family life and possessed all sorts of affection from six adults (parents and grandparents) the moment they were born. They enjoy an affluent material life which is far beyond the imagination of people born in earlier years - the modern lifestyle and consumption consciousness of fashion show have been taken as their value orientation for material needs-brand concept has enlarged their international view.

At the same time, they are a generation of pet growing with the internet. Cultural and entertainment information provided by mobile phones, Broad Brand as well as the ever updating digital products has always been flooding in their spiritual life, and offering them a boundless information world, or a free intellectual space, which has expanded their views and knowledge scope, and enabled them to, more or less, forwardly make intellectual trials of integrating and constructing inner situations in cyber space-internet culture has led them into an open world where they have made trials of "determining" in self-realization.

The mainstream society has continuously highlighted their concerns on this - compared to those born earlier, will this generation of virtually icing on the cake be spoiled children wanting in a sense of responsibility?

Now, this tough problem should be resolved with designs and plans set by academic education.

\section{ACADEMIC EDUCATION CAN REALIZE THE INTELLECTUAL INDEPENDENCE IN LEARNERS}

The cultural tradition of emphasizing education has started since ancient times in China, let alone the facts of the only-child group and abundant economy, therefore, the early education concepts became popular from the 1990s. A sound example is the education slogan "do not lose at the starting line"-it demonstrated that the post 90s undergraduates have generally accepted systematic education and intellectual development in their early years with some of them even skilled obtained, with the addition that passing all the entrance exams in primary schools, middle schools and universities has naturally enhanced their superiority complex - enough confidence, strong pride, dislikes for spoon-feed and preach-teaching. However, the teaching styles of spoon-feed and preaching, which inevitably come to meet exam-oriented education, have made them tired and exhausted, with no will to recall. They are desperate to brand new learning context, teaching methods and personal development in academic life.

The top priority for academic education is to be soberly aware that the post 90s undergraduates are still winners in exam-oriented education - the source of their confidence. And exam-oriented education sticks firmly to the "learning theories" originated in the behavioral psychology at the beginning of the 20th century. Its negative side is putting the focus of teaching on students' learning behaviors instead of the reason for spurring students in taking certain reaction or special thinking mode. It calls for students' efforts to repeat those so-called "important" aspects or steps, while pays rare attention to their understanding and handling of questions, and even ignores the cultivation, consolidation and improvement of their subject logical ability, which is the very intellectual source for students to independently get answers from insufficient reactions. For this reason, learning and training in exam-oriented education has regulated students' subject behavior reaction, nevertheless, it neglects fostering students' understanding and creativity in face of the future [1]. Second, faced with young groups of post 90s students, academic education must play a chief role in qualitatively changing these students lost in the past achievement into "learners" brave in exploring the unknown, improving capacity and sublimating intelligence in knowledge area. The knowledge the post 90s students have obtained before colleges and universities is simple stuff generally stable, self-contained, objective and well-structured (including network information). Since knowledge of this kind can be 
recorded and seized in certain ways, can be processed, stored up and distributed, they can be segmented, can be expressed with languages and symbols, can be packed and passed on in existing ways. In teaching works in accordance with concept of simple knowledge, teachers deliver, impart and broadcast their knowledge to students in a commanding and irrefutable way, supplementary bring them some practices to help them have wide learning and a retentive memory. In this way, students are only passive individuals copying, assimilating, accumulating and finally broadcasting what they are taught ${ }^{[1]}$.In the teaching mode under the double leading of "learning theories" of behaviorism and view of simple knowledge, it is very easy to accelerate the formation of dependent personality in educatees:

1. Not able to make decisions on their daily learning behaviors without the clear suggestions from teachers.

2. Happy to invite teachers to make important decisions for them, while hard to make and carry out studying plans independently.

3. Always afflicted with worries of being neglected or abandoned by teachers.

4. Very easy to get harmed for criticized, or not being praised by teachers [2].

On the contrary, "learners" in academic education are behavioral agents who are good at independently, adeptly and sagaciously setting up meanings in the process of intellectual self-exploration. So what should be propelled in academic education and teaching is to let learners achieve self-realization and self-enhancement independently and intellectually during the course of appreciating knowledge complicacy.

In fact, as knowledge approaches closer and closer to expertise and the leading edge, it naturally loses its stability and sound constructive properties. After learners have taken a good command of professional logical rules, the formation and deduction of knowledge becomes closely bound to learners' intellectual apprehending and experienced planning, that's to say, it is connected with learners' persevere exploration and foresight in specific situation. Therefore, the so-called knowledge development always covers the faith of pursuing truth cherished by certain learners during exploring and questioning, and the situational endeavor venation of newly understanding and constructing specific knowledge links or systems due to faith-keeping. Knowledge complexity converges on openness and negative effects of its structure, situational and consultative characteristics of leading progresses. Based on this, frontier knowledge can's be mastered and broadcast in stable and isolated ways; instead, it can only be effectively obtained through appreciating and apprehending the various aspects of its systematic $\operatorname{organism}^{[1]}$. Hence real learners need an active, perspective and positive attitude towards life and faithful, purposeful and independent personality traits, which are also the concentration of academic education. When it comes to growth planning for the post 90s, education and teaching should map out a targeted plan for all the development links and promote them to realize the magnificent change from "students" to "learners".

\section{LEARNERS CAN ASSUME THE RESPONSIBILITY OF EXPLORING A HAPPY LIFE}

On July 17, 2012, premier Wen Jiabao stressed at the National Employment and Entrepreneurship Commending Assembly:" Employment is vital to people's livelihood." It can be analyzed in broad sense that it explicitly implies that the successful academic education should not only ensure a good life at present for every post 90s student, but also support them in seizing and planning their future life.

Academic education corresponds to career life of every learner, so it cannot be more important to assist and support them on school days in facing up to and probing into their career life. The "career" mentioned here is a term in its broad sense, and it is defined by the most influential American educator John Dewey in the world since the 20th century. John Dewey mentioned in his masterpiece Democracy and Education that all sorts of education carry the professional nature, but "career is nothing but the a direction one should follow in his life so as to let the doer feels fulfilled for the achievement of the activity, and also make his friends feel the activity is good for them."'[3]'According to John Dewey, it is the purpose of career at lowest level to obtain necessities of life through career. Career is not only a bond connecting individuals and the society, but also the most important component of individual life in modern society.

From the tendency of social development, the trend of informationization, integration and cooperation is irreversible, from this sense academic education should be practical, and focus on promoting learners' growth of knowledge and intelligence, improving and completing their moral integrity, cultivating their vocational ability, and strives to maintain unity and wholeness among the three. In the era of informationization, with integration of the knowledge getting higher and higher, humanities and natural science form the essential foundation of humanity and future development and technical innovation. They only provide gains both in material and spiritual in the condition that learners apply them at the core of vocational activity.

Academic education offers professional training, career development and broad learning, it not only enables learners to receive academic education and training, cultivation of ability and experience, but also reap enlightenment and influence in humanities which lay a solid foundation for their pursuit of personal interests and humanities. According to Wikipedia, ego is a kind of self consciousness of human individual about their own monolithic existence. Typically, human individuals regard themselves as a unique cultural entity which is continuous, integrated and inseparable. The learners completing triumphant return in academic education will also realize self-independence at the same time. In this way, depending on their accumulation of quality and literacy from academic education, they would persist in carrying an internal and external adjustment so as to be recognized by the society and keep balance between individual talents and social value, only by doing this can they find and boost their happiness. It cannot be denied that academic education have a abiding influence on each learner's life, and the broad learning and intensified career development offered by it lay 
a sound foundation for their social awareness and abilities, and also make it accessible for the growth of their knowledge, morality and intellectual. When thinking on Premier Wen's "employment is vital to people's livelihood", one will delightedly find that thousands of graduation post 90's lay the groundwork for keeping social developing soundly through their arduous efforts in vocational activity; and various vibrant vocational activities also push forward social progress, make it possible for fellow countrymen and even whole human society to live in great bliss while meeting social needs.

John Dewey believes that career, from an extreme sense, is the continuous development of intellectual and morality [4].Therefore, that learners post 90s must change from "students" into "learners" which we have been advocated is actually the foundation of career planning for college student. Depending on their independent selfhood, learners can apply, integrate and organize what they have learned to deal with professional subject, deepen and master all kinds of rudimentary Knowledge, and then apply it into practice properly and innovatively. In this way, the growth of intellectual and conviction is already underway... The upgrading of professional competence facilitated hence enables learners to have a logistic intelligence which makes it possible for them to classify and arrange social facts, experience and information. With rational, normal and humane achievement experience, this kind of living and dynamic knowledge system and application will be bound to enhance their moral consciousness...

In this way, the learner's vocational planning become the carrier for development of individual spirit and qualities, and also the meeting point of their knowledge, intellectual ,faith and moral development. Practical significance of this can be listed as follows: In the first place, the parlous state of the economy, vagaries of evolutionary technology and comprehensiveness of professional posts are always blurring the boundary between supervisor and the supervisee. Therefore, one should learn to think about social life, and has a flexible and open mind so as to have a better understanding of modern society and win more chances for self-development. Second, modern society presenting little hints at future social needs on vocation provides unlimited room to grow for everyone, so it should be a frequent habit to improve vocational ability, and the ability of independent judgment, making correct choice and moral control are elevated at the same time. Third, the accumulation of humanities and scientific knowledge helps embolden practitioners, make them avoid blindly meeting the requirements and bondage of current professional environment, and duly make breakthrough with intelligence. By doing this, they gradually realize the perfection of their personalities and consolidation of social responsibilities.

In 1900s, the UNESCO issued Mass Education Declaration; calling on education around the world should get rid of the "elite education", and making quality education available to the public. On March 14, 2006, in the press conference of the Fourth Session of the Tenth National People's Congress, Premier Wen also stressed that "make education available to the public". The two acclimations agree with each other in concept, and colleges should really implement and promote the "mass education". The overstatement of "elite education" leads to the concept of elite vulgar, superficial and utilitarian for a long period---it seems that once stepping into a college, one is an elite; college graduates are expected to be at the professional post called "golden rice bowl" or "iron rice bowl"; only once becoming a famous person with glory, one's life can be called a success one. All of these perspectives not only fails to achieve significant change from students to learners, but also dilutes the knowledge, capacity, intellectual, faith and moral perfection which are obtained through arduous learning and should be working during the process of career planning. If this persists in, academic education will lose its intrinsic function and descends to gold-plate factories. The concept of carrying forward "mass education" does not mean to decrease of education level, but makes quality education to the public, ensures each learner has high diathesis, and helps every learner to strive for a happier life. The concept of carrying forward "mass education" does not mean decreasing education level, but makes quality education to the public, ensures each learner has high diathesis, and helps every learner to strive for a happier life.

\section{ACKNOWLEDGEMENTS}

*Correspongding Author: He guo-zhu. Sichuan Agricultural University, 611830.

\section{REFERENCES}

[1] David H Jonathan, Theoretical Foundation of Learning Environment, Tainian Zheng, Youqun Ren, East China Normal University Press, 2002.

[2] Fajian Yi etc, Psychologist, Chongqing University Press, 1996.

[3] John Dewey, Democracy and Education, translated by Chenxu Wang, People's Education Press, 1990.

[4] Yongqiang Wang, On Dewey's vocational Education, master's thesis. 